\title{
Cloud representation in general-circulation models over the northern Pacific Ocean: A EUROCS intercomparison study
}

\author{
By A. P. SIEBESMA ${ }^{1 *}$, C. JAKOB ${ }^{2}$, G. LENDERINK $^{1}$, R. A. J. NEGGERS ${ }^{1,3}$, J. TEIXEIRA ${ }^{4}$, \\ E. VAN MEIJGAARD ${ }^{1}$, J. CALVO ${ }^{5}$, A. CHLOND ${ }^{6}$, H. GRENIER ${ }^{7}$, C. JONES ${ }^{8}$, M. KÖHLER ${ }^{9}$ \\ H. KITAGAWA ${ }^{10}$, P. MARQUET ${ }^{7}$, A. P. LOCK ${ }^{11}$, F. MÜLLER ${ }^{6}$, D. OLMEDA ${ }^{5}$ and C. SEVERIJNS ${ }^{1}$ \\ ${ }^{1}$ Royal Netherlands Meteorological Institute (KNMI), The Netherlands \\ ${ }^{2}$ Bureau of Meteorology, Melbourne, Australia \\ ${ }^{3}$ University of California, Los Angeles, USA \\ ${ }^{4}$ Naval Research Laboratory, Monterey, USA \\ ${ }^{5}$ Instituto Nacional de Meteorologia, Madrid, Spain \\ ${ }^{6}$ Max-Planck Institut für Meteorologie, Hamburg, Germany \\ ${ }^{7}$ Météo-France (CNRM/GAME), Toulouse, France \\ ${ }^{8}$ Rossby Climate Center, Norrköping, Sweden \\ ${ }^{9}$ European Centre for Medium-Range Weather Forecasts, Reading, UK \\ ${ }^{10}$ Japan Meteorological Agency, Tokyo, Japan \\ ${ }^{11}$ Met Office, Exeter, UK
}

(Received 4 August 2003; revised 19 April 2004)

\section{SUMMARY}

The EUROCS (EUROpean Cloud Systems study) project aims to improve the treatment of cloud systems in regional and global climate and weather prediction models. This paper reports an intercomparison study of cloud representation over the Pacific Ocean for nine climate and weather prediction models. The study consists of an analysis of a June/July/August 1998 period along an idealized trajectory over the Pacific Ocean that encompasses both the ascending and descending branch of the Hadley circulation. The three cloud types that are studied by EUROCS, stratocumulus, shallow cumulus and deep-convective cloud systems, do all occur in a persistent and geographically separated way, along this trajectory.

The main focus of this study is on processes related to the hydrological cycle within the Hadley circulation. These include the large-scale dynamics (i.e. the strength of the up- and downwelling branches of the Hadley cell), the cloud processes (i.e. cloud cover, cloud amounts and precipitation), and the impact of these processes on the radiation budget both at the top of the atmosphere and at the ocean's surface.

In order to make a quantitative assessment, special care has been taken to select reliable observational datasets. The main conclusions are that (1) almost all models strongly underpredicted both cloud cover and cloud amount in the stratocumulus regions while (2) the situation is opposite in the trade-wind region and the tropics where cloud cover and cloud amount are overpredicted by most models. These deficiencies result in an overprediction of the downwelling surface short-wave radiation of typically $60 \mathrm{~W} \mathrm{~m}^{-2}$ in the stratocumulus regimes and a similar underprediction of $60 \mathrm{~W} \mathrm{~m}^{-2}$ in the trade-wind regions and in the intertropical convergence zone (ITCZ). Similar biases for the short-wave radiation were found at the top of the atmosphere, while discrepancies in the outgoing long-wave radiation are most pronounced in the ITCZ.

KEYWORDS: Clouds Convection Radiation

\section{INTRODUCTION}

The representation of clouds in general-circulation models (GCMs) remains one of the most important as yet unresolved issues in atmospheric modelling. This is partially due to the overwhelming variety of clouds observed in the atmosphere, but even more so due to the large number of physical processes governing cloud formation and evolution as well as the great complexity of their interactions. Model improvement necessarily begins with an assessment of current model performance and the identification of model shortcomings. For cloud parametrizations a number of assessment techniques have been developed and applied, ranging from broad model climate evaluation to detailed process case studies.

* Corresponding author: Royal Netherlands Meteorological Institute (KNMI), PO Box 201, 3730 AE De Bilt, The Netherlands. e-mail: siebesma@knmi.nl

(C) Royal Meteorological Society, 2004. A. P. Lock's contribution is Crown copyright. 
The EUROCS (EUROpean Cloud Systems study) project aims to improve the treatment of cloud systems in regional and global climate and numerical weather prediction (NWP) models. The strategy used in EUROCS is based on the use of a hierarchy of models and observations to integrate cloud studies across the full range of scales; improved parametrizations of cloud processes are developed by comparing single-column model (SCM) simulations to cloud-resolving models (CRM) and largeeddy simulation (LES) models for a number of well documented cases. This technique has been pioneered by the GEWEX Cloud System Study (GCSS) (Browning 1993; Randall et al. 2003) and is now considered a well established approach to model evaluation and improvement. It relies on results of a small number of isolated case studies carried out for various cloud types such as stratocumulus, shallow cumulus and deep convective clouds. While extremely useful in identifying flaws in the formulation of parametrizations, it is not immediately obvious how to transfer findings of those studies to the full GCM. This is partly due to the (desired) absence of feedback processes onto the large scale in SCM/CRM/LES studies, but also results from the possibility that the large-scale conditions prescribed in the SCM/CRM simulations might be nonrepresentative for both the real and model atmospheres.

Jakob (2003) has argued that a better link between the 'mean' results of a GCM and case studies needs to be established by evaluating GCM results in terms of cloud regimes. Techniques for such a cloud-regime-driven model analysis have been developed and used in a variety of studies (e.g. Klein and Jakob 1999; Tselioudis et al. 2000; Webb et al. 2001; Norris and Weaver 2001; Tselioudis and Jakob 2002; Williams et al. 2003). While very useful, the complexity of the techniques used in these studies has usually limited their application to either a single or a small number of models. Since it is the aim of EUROCS to evaluate cloud and convection parametrizations in a large number of GCMs and for a variety of cloud types, the application of complex techniques to all of the participating models is difficult. Hence, in this study we aim to develop and apply a simpler approach to cloud-regime oriented model evaluation.

The cloud types studied by EUROCS include stratocumulus, shallow cumulus and deep convective cloud systems (Duynkerke et al. 2004; Lenderink et al. 2004; Guichard et al. 2004). Fortunately, these cloud types do occur in nature in reasonable geographic separation as the predominant regimes in the ascending and descending branches of the Hadley circulation. It is, therefore, possible to isolate regimes geographically by following an idealized trajectory along the inflow into the ITCZ. For that purpose, model simulations with nine large-scale models are carried out for June/July/August (JJA) 1998 and the quality of their results are assessed along a cross-section in the subtropical and tropical North Pacific ranging from $\left(235^{\circ} \mathrm{E}, 35^{\circ} \mathrm{N}\right)$ to $\left(187.5^{\circ} \mathrm{E}, 1^{\circ} \mathrm{S}\right)$. The main goals we hope to achieve through this assessment are:

- to document the performance quality of state-of-the-art GCMs in modelling the first-order characteristics of subtropical and tropical cloud systems;

- to provide an additional simple test-bed for parametrizations in GCMs by establishing a reference observational data set for the evaluation of cloud systems contained in the Hadley circulation;

- to establish a broader context for the results of the SCM studies that form a main part of EUROCS.

It is worthwhile pointing out that, as for all multi-model studies, the aim of the model evaluation carried out here needs to remain broad. Studies like this cannot and will not solve all problems in all participating models. They will, however, provide guidance as to where major efforts need to be directed both in individual modelling 
TABLE 1. KEY CHARACTERISTICS OF THE PARTICIPATING MODELS

\begin{tabular}{|c|c|c|c|c|c|c|}
\hline Model & Type & Domain & Model reference & Scientist & $\begin{array}{l}\text { Horizontal } \\
\text { resolution }\end{array}$ & $\begin{array}{l}\text { Vertical } \\
\text { levels }\end{array}$ \\
\hline ARPEGE $3.22 \mathrm{a}$ & Climate & Global & Gibelin and Déqué (2003) & $\begin{array}{l}\text { Grenier } \\
\text { Marquet }\end{array}$ & T63 & 45 \\
\hline ECHAM 5.0.9 & Climate & Global & Roeckner et al. (1996) & $\begin{array}{l}\text { Chlond } \\
\text { Muller }\end{array}$ & $\mathrm{T} 42$ & 19 \\
\hline SPEEDY 7 & Climate & Global & Molteni (1996) & Severijns & $\mathrm{T} 30$ & 7 \\
\hline ECMWF 23r4 & Weather & Global & Gregory et al. (2000) & Koehler & T159 & 31 \\
\hline MetO & Weather & Global & Webster et al. (2003) & Lock & $2.5^{\circ} \times 3.75^{\circ}$ & 38 \\
\hline JMA gsm0103 & Weather & Global & Matsumura et al. (2002) & Kitagawa & $\mathrm{T} 106$ & 40 \\
\hline RACMO 2 & Climate & Regional & Lenderink et al. (2003) & Meijgaard & $0.5^{\circ} \times 0.5^{\circ}$ & 40 \\
\hline RCA 2 & Climate & Regional & Jones (2001) & Jones & $0.5^{\circ} \times 0.5^{\circ}$ & 40 \\
\hline HIRLAM 5.1.4 & Weather & Regional & Undén et al. (2002) & Calvo & $0.5^{\circ} \times 0.5^{\circ}$ & 40 \\
\hline
\end{tabular}

groups and the wider research community and will provide a reference point for future work. The identification of specific errors in individual models usually requires more sophisticated analysis techniques and is consequently left to the individual modeldevelopment groups. An example for such individual model assessment using the approach developed here can be found in the study of Lock (2004).

Section 2 provides a description of the participating models and the set-up of the experiments. Section 3 summarizes the various observations used in the study. Section 4 contains the main results of the comparison followed by a discussion and resulting conclusions in section 5 .

\section{CASE SET-UP AND PARTICIPATING MODELS}

The intercomparison is based on simulations by nine different models. These include three global climate models (ARPEGE, ECHAM, SPEEDY), three global numerical weather prediction models (ECMWF, MetO, JMA) and three regional models (RACMO, RCA - climate, HIRLAM - weather prediction). For a short description of the models refer to the appendix. Table 1 lists the responsible scientists, the model names, versions and types, references to full model descriptions and model resolution. It is sufficient here to note that all three regional models (RACMO, RCA, HIRLAM) use the same dynamics. Differences between these models can thus be completely attributed to differences in the physics parametrization. ECMWF and RACMO, on the other hand, use exactly the same physics parametrization packages. Differences between these models, therefore, reside in the dynamics.

Figure 1 shows the 13 locations along the cross-section used throughout this study, along with the observed cloud cover averaged over the selected three-month period. The observed cloud-cover fields are obtained from the International Satellite Cloud Climatology Project (ISCCP, see Rossow et al. 1991). It starts in the north-east Pacific off the coast of California where the downwelling branch of the Hadley circulation over a cold Pacific Ocean causes persistent solid stratocumulus decks (between $35^{\circ}$ and $25^{\circ} \mathrm{N}$ ). Subsequently, the cross-section enters the trade-wind region in which the stratocumulus breaks up into scattered shallow cumulus fields (between $25^{\circ}$ and $15^{\circ} \mathrm{N}$ ) and finally ends in the ITCZ that is characterized by deep convective cumulus towers. The transect, therefore, encompasses three areas, each dominated by a cloud type that has been subject of isolated case studies within the EUROCS project (Duynkerke et al. 2004; Lenderink et al. 2004; Guichard et al. 2004).

All participating modellers were asked to send in model output for the 13 locations, starting at $\left(35^{\circ} \mathrm{N}, 235^{\circ} \mathrm{E}\right)$ and moving south-westwards with steps of $4^{\circ}$ longitude and 

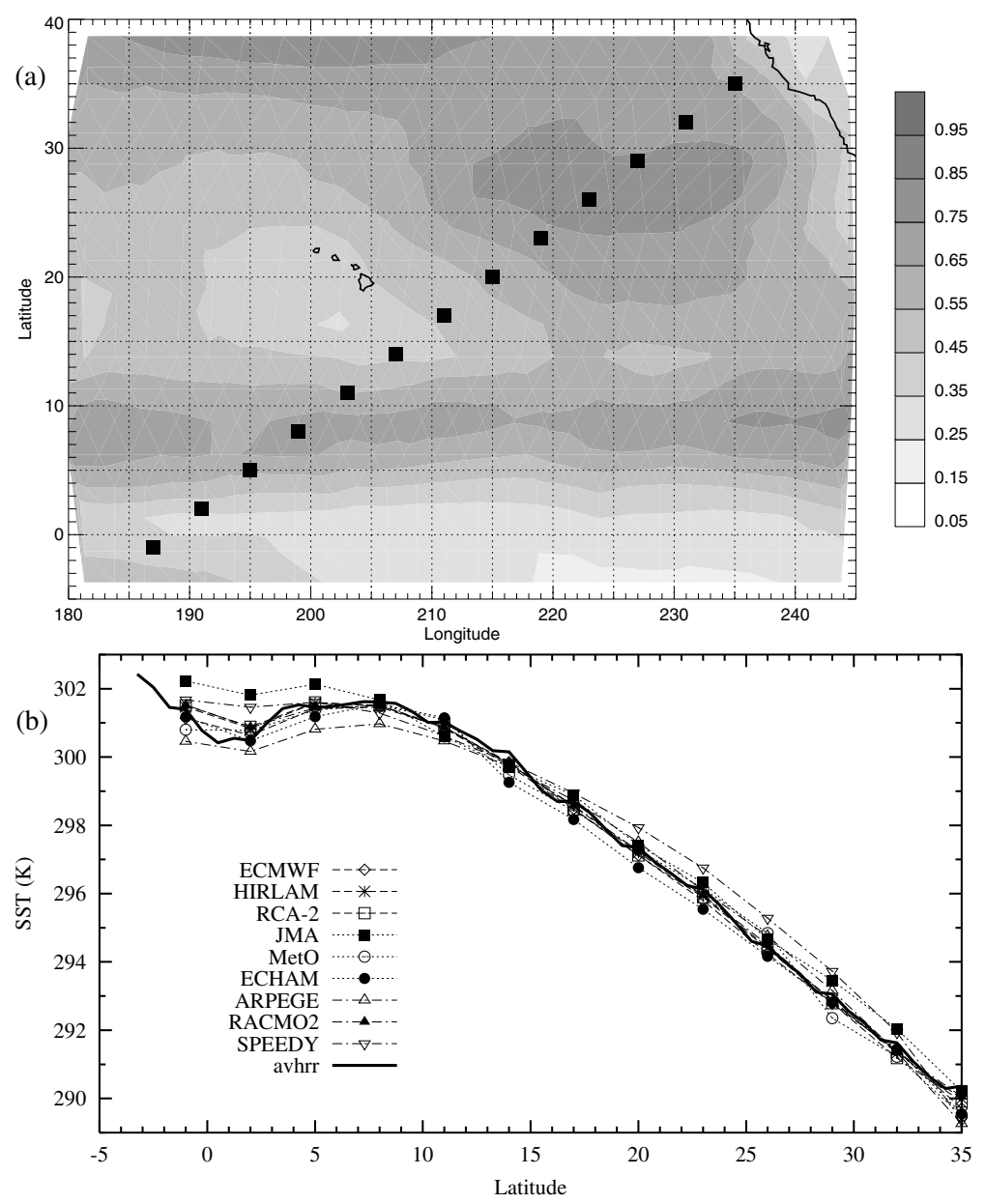

Figure 1. (a) The proposed cross-section with the 13 locations from which model output is requested. The same figure also shows the International Satellite Cloud Climatology Project observed cloud cover for the June/July/August 1998 period. (b) The prescribed sea surface temperatures used in the models along with observations based on AVHRR data.

$3^{\circ}$ latitude until $\left(1^{\circ} \mathrm{S}, 187.5^{\circ} \mathrm{E}\right)$. As all modellers were free to choose their model resolutions, the model output should simply originate from model grid points that are closest to the requested locations. The only imposed restrictions were that the models had to run in climate mode (i.e. without data assimilation) and with a prescribed sea surface temperature (SST). All three participating regional models used the same lateral boundary fields that were obtained from the ECMWF* model.

As the Hadley cell is a well defined circulation, we consider it sufficient to use a relatively short period for the analysis of model deficiencies. JJA 1998 was selected as that period, largely because the SST anomaly along the cross-section for that period was less than $1 \mathrm{~K}$. Therefore, the monthly-mean deviations from climatology for most of the cloud parameters are expected to be small.

Merely as a check on whether all models were subjected to similar boundary conditions, we show in Fig. 1 the JJA-average prescribed SSTs used by all nine models,

* European Centre for Medium-Range Weather Forecasts. 
along with the AVHRR* satellite data using the optimum interpolation (OI) version 2 method (Reynolds et al. 2002). Basically three regimes can be identified: (1) an almost linear rise of the SST along the trades from about $290 \mathrm{~K}$, typical of stratocumulus situations at $35^{\circ} \mathrm{N}$ to values of around $301 \mathrm{~K}$ at about $10^{\circ} \mathrm{N}$; (2) an almost constant value from $10^{\circ} \mathrm{N}$ to $5^{\circ} \mathrm{N}$ (the ITCZ) and (3) a slight decrease toward the equator. There is some scatter between the different models, but the standard deviation is within the range of variability in the observations. Only the SSTs used by the JMA and SPEEDY models are systematically too warm, up to values close to $1^{\circ}$.

Participants were requested to send in monthly-mean results for $0,3,6, \ldots$, 21 UTC. In this way, model data are available for both the month-to-month variability and the (monthly-average) diurnal cycle. Two types of model data were requested for the 13 locations: (1) vertical profiles for a number of atmospheric fields; and (2) single-level parameters for several vertically integrated fields, fluxes at the top of the atmosphere fluxes, and fluxes near the surface. A complete list of fields, data and results can be found on the web $†$. In this paper we present and discuss only the main results.

\section{OBSERVATIONAL DATASETS}

A number of different satellite-based observational datasets have been used for this intercomparison. As space-borne remote-sensing techniques have not (yet) reached the level of providing reliable data with a high-resolution vertical structure, they are restricted to three types of observation:

- top of the atmosphere (radiative) fluxes;

- vertically integrated fields (cloud cover, liquid water path etc.) and precipitation;

- surface fields and surface radiative fluxes.

It should be noted that there is an increasing level of uncertainty for these types of observation. The top-of-the-atmosphere (TOA) fluxes are almost direct measurements and are, as such, the most reliable. For the second class of observations various assumptions on, for instance, the effective droplet size need to be made, while for the third class even further additional assumptions on the vertical structure are used in conjunction with a radiative-transfer model in order to assess the surface radiative fluxes (Wielicki et al. 1996).

Most of the observational data used in the rectangle that spans the prescribed crosssection has been made easily accessible by the GEWEX $¥$ Cloud-System Study Data Integration for Model Evaluation (GCSS-DIME) on the web§. Table 2 provides an overview of the satellite products used, and the archives where the data can be found. Monthly averages are calculated of all datasets. The horizontal resolutions may differ, as each instrument or merged group of instruments has its/their own precision. However, as with the model data, no interpolation is used in the calculation for the average values of the various fields on the 13 points of the cross-section on the diagonals; the values are taken from the grid points closest to the points on the diagonal.

TOA radiative flux observations used in this study are provided by the Clouds and the Earth's Radiant Energy System (CERES, see Wielicki et al. 1996). The instruments are carried by the Tropical Rainfall Measurement Mission satellite (TRMM, see Simpson et al. 1996; Kummerow et al. 1998), launched in November 1997. Dataset ES9

\footnotetext{
* Advanced Very-High Resolution Radiometer.

$\dagger$ http://www.knmi.nl/samenw/eurocs

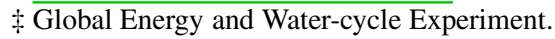

$\S$ http://gcss-dime.giss.nasa.gov/index.html
} 
TABLE 2. THE VARIOUS ARCHIVES, THE OBSERVATIONAL DATASETS AND THEIR SPECIFICS, AND THE MEASURED PARAMETERS USED IN THIS STUDY (SEE TEXT FOR AN EXPLANATION OF THE ACRONYMS)

\begin{tabular}{|c|c|c|c|c|c|}
\hline Archive & Dataset & Platform & Resolution & Frequency & Parameters \\
\hline $\begin{array}{l}\text { NASA Langley } \\
\text { ASDC }\end{array}$ & CERES ES9 & TRMM & $2.5^{\circ} \times 2.5^{\circ}$ & $\begin{array}{l}\text { Monthly } \\
\text { averages }\end{array}$ & $\begin{array}{l}\text { TOA radiative fluxes } \\
\text { Surface short-wave fluxes }\end{array}$ \\
\hline $\begin{array}{l}\text { RSS, } \\
\text { GCSS-DIME }\end{array}$ & $\mathrm{SSM} / \mathrm{I}$ & $\begin{array}{c}\text { DMSP } \\
\text { F11, F12, F14 }\end{array}$ & $0.25^{\circ} \times 0.25^{\circ}$ & Two per day & $\begin{array}{l}\text { Liquid-water path } \\
\text { Water vapour column }\end{array}$ \\
\hline ISCCP & D1 & based on DX & $2.5^{\circ} \times 2.5^{\circ}$ & Three hourly & Cloud cover \\
\hline $\begin{array}{l}\text { GCSS-DIME } \\
\text { NASA GSFC }\end{array}$ & GPCP v.2 & NOAA, gauges & $1.0^{\circ} \times 1.0^{\circ}$ & Daily & Precipitation rate \\
\hline $\begin{array}{l}\text { GCSS-DIME } \\
\text { NASA GSFC }\end{array}$ & TRMM 3B42 & TRMM & $1.0^{\circ} \times 1.0^{\circ}$ & Daily & Precipitation rate \\
\hline NCEP & OI & AVHRR & $1.0^{\circ} \times 1.0^{\circ}$ & Monthly & Sea surface temperature \\
\hline
\end{tabular}

CERES: Clouds and the Earth's Radiant Energy System.

TRMM: Tropical Rainfall Measurement Mission.

TOA: Top of the atmosphere.

SSMI: Special Sensor Microwave/Imager.

DMSP: Defense Meteorological Satellite Program.

D1: Gridded cloud product of the International Satellite Cloud Climatology Project.

DX: Pixel-level cloud product of the International Satellite Cloud Climatology Project.

GPCP: Global Precipitation Climatology Project.

NOAA: National Oceanic and Atmospheric Administration.

OI: Optimal interpolation.

AVHRR: Advanced Very-High-Resolution Radiometer.

contains monthly regional averages on a $2.5^{\circ} \times 2.5^{\circ}$ grid of the TOA fluxes, of which we used the outgoing long-wave radiation (OLR), the net short-wave radiation and the cloud radiative forcing.

Cloud-cover fields are obtained from ISCCP (Rossow et al. 1991). A hierarchy of geostationary (GOES, GMS, METEOSAT) and polar orbiting (NOAA*) satellites are used by ISCCP to produce a number of cloud products. In the present study the D1 data set is used for cloud cover estimates on a three-hourly timescale and a $2.5^{\circ}$ spatial resolution.

Liquid-water path and water-vapour column data are derived from measurements by the Special Sensor Microwave/Imager (SSM/I, see Hollinger 1987). The SSM/I data and images are produced by Remote Sensing Systems (RSSs) and sponsored by the NASA $\uparrow$ Pathfinder Program for early Earth Observing System (EOS) products. The SSM/I is situated on polar-orbiting satellites flown by the Defense Meteorological Satellite Program (DMSP), the first of which was launched in June 1987. The RSS generates SSM/I data products using a unified physically based algorithm to retrieve simultaneously ocean wind speed (at $10 \mathrm{~m}$ ), water vapour, cloud water, and rain rate (Wentz 1997; Wentz and Spencer 1998). Three DMSP satellites carrying SSM/I (F11, F13 and F14) were operational during our period of interest.

The surface precipitation rate was obtained from the Global Precipitation Climatology Project (GPCP, see Huffman et al. 1997; Huffman 1997). The general approach of GPCP is to combine the precipitation information available from each of several sources into a final merged product, taking advantage of the strengths of each data type. Microwave estimates are based on SSM/I, infrared (IR) precipitation estimates are obtained from geostationary satellites and polar-orbiting satellites, and gauge data are assembled and analysed by the Global Precipitation Climatology Centre (GPCC).

\footnotetext{
* National Oceanic and Atmospheric Administration.

$\dagger$ National Aeronautics and Space Administration.
} 
The GPCP Version 2 combination includes precipitation estimates from TOVS* and NOAA OPI $\dagger$ data, permitting filling data voids at high latitudes that occurred in Version 1 . The $1^{\circ}$ daily product (1DD) in the band $40^{\circ} \mathrm{N}-40^{\circ} \mathrm{S}$ was used. Another source for precipitation measurements is TRMM. Dataset 3B42 contains daily averaged adjusted merged-IR estimates, generated by combining measurements by the TRMM Visible and Infrared Scanner (VIRS) and the TRMM Microwave Imager (TMI) (e.g. Huffman et al. 1995).The TRMM 3B42 datasets were provided by the Distributed Active Archive System (DAAC) of the NASA Goddard Space Flight Center (GSFC).

Surface radiative fluxes (both long wave and short wave) were derived using the CERES instrument data in conjunction with a radiative-transfer model (Wielicki et al. 1996). As no reliable observations of surface latent- and sensible-heat fluxes are available, we used the climatology based on da Silva et al. (1994) and model reanalysis results of ECMWF and NCEP\$.

Finally we use ECMWF reanalysis products for evaluation of the vertical structure of various fields, although we are well aware that reanalysis fields are not real observations. Nevertheless, at present, these are the only products that are available for analysing vertical structure.

\section{RESULTS}

In this section we discuss the fundamental results of this intercomparison. We therefore limit ourselves to three-month averages for the whole JJA 1998 simulation period.

First we present cross-sections of vertical velocity, relative humidity and cloud cover in order to illustrate the model-to-model variability in the spatial structure of these fields. As a reference, we also show the ECMWF reanalysis results. Because of the very coarse vertical resolution, we exclude results from SPEEDY for this part. Secondly, we evaluate single-level model fields that are relevant for the hydrological cycle compared with observations and, finally, we explore the implications on the radiation budget.

\section{(a) Cross-sections}

Cross-sections with the vertical velocity are displayed in Fig. 2. All models seem to produce a reasonable qualitative picture of the Hadley circulation, with a narrow area of upward vertical velocities in the deep-convection region and a large area of downward motion in the subtropical free troposphere cumulating in a maximum of the subsidence values at around $35^{\circ} \mathrm{N}$. In detail, however, the models show substantial differences. Only the ECMWF and MetO vertical-velocity fields are similar to the ECMWF reanalysis, which has a strong and narrow upward branch with velocities up to $0.1 \mathrm{~Pa} \mathrm{~s}^{-1}$ in the ITCZ between $5^{\circ} \mathrm{N}$ and $10^{\circ} \mathrm{N}$, and the strongest subsidence values in the stratocumulus $(\mathrm{Sc})$ regions. The other models show either weaker and/or shallower upward branches. In the Sc region between $35^{\circ} \mathrm{N}$ and $25^{\circ} \mathrm{N}$, the subsidence velocity in ECMWF, ECHAM, MetO and RACMO is, on average, around $0.04 \mathrm{~Pa} \mathrm{~s}^{-1}$ in the free atmosphere just above the observed Sc cloud tops (at approximately $900 \mathrm{hPa}$ ). This value is close to what one would expect from assuming background radiatively driven subsidence (Betts and Ridgway 1988). ARPEGE and JMA have slightly lower subsidence values of around $0.02-0.03 \mathrm{~Pa} \mathrm{~s}^{-1}$, while HIRLAM and RCA have virtually no subsidence.

\footnotetext{
* TIROS (Television Infrared Observation Satellite) Operational Vertical Sounder.

$\dagger$ Outgoing long-wave-radiation based Precipitation Index.

$\$$ National Centers for Environmental Prediction.
} 

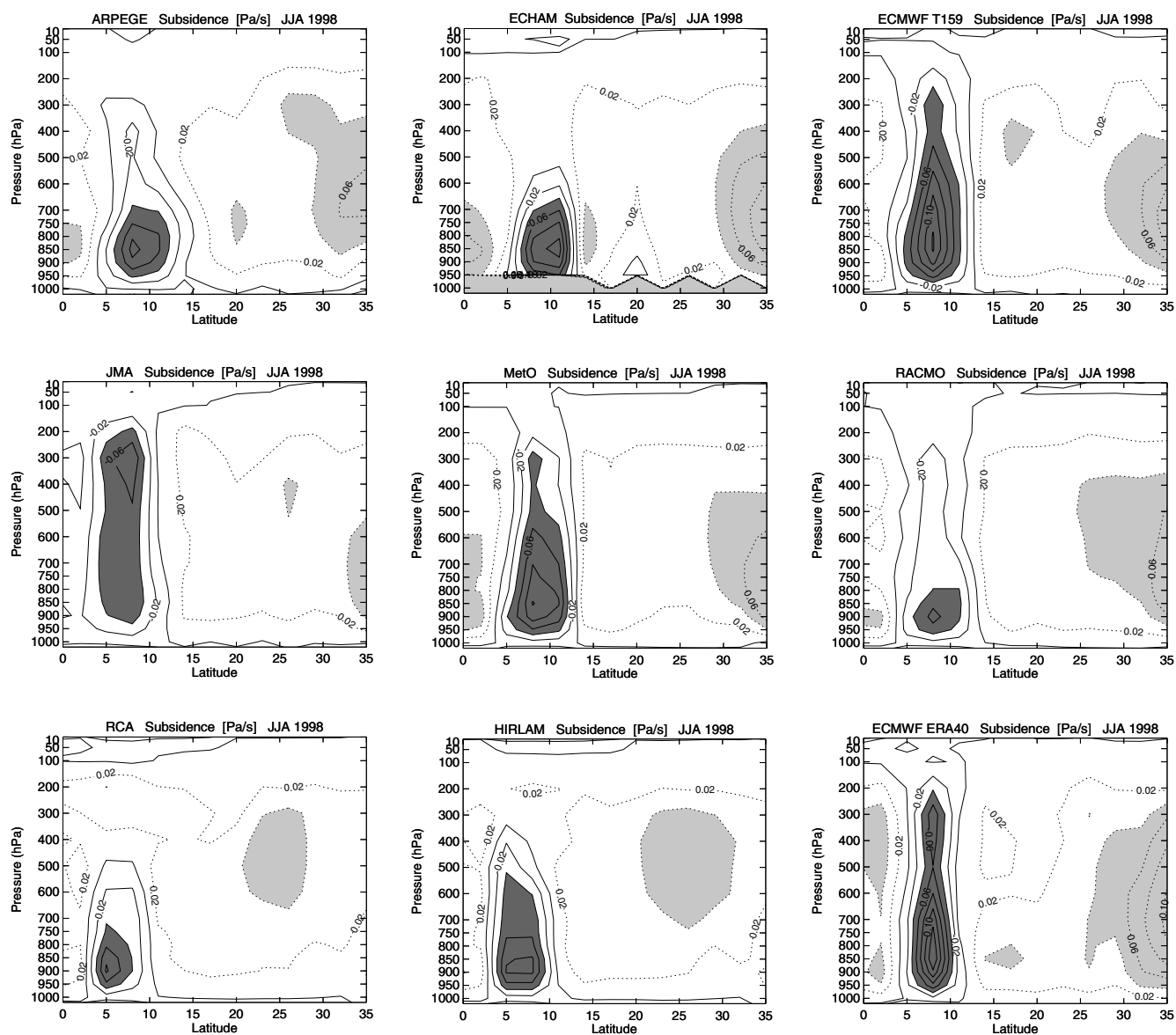

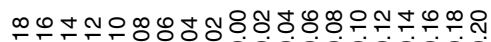

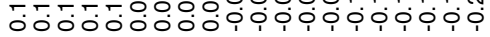

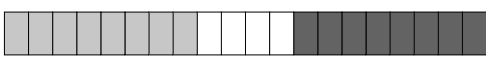

Figure 2. June/July/August averaged cross-sections of vertical velocity. Top panels (left to right) show ARPEGE, ECHAM and ECMWF. Middle panels (left to right) show JMA, MetO and RACMO. Bottom panels (left to right) show RCA, HIRLAM and, as a reference, the ECMWF analysis.

It is difficult to argue about the reasons for these differences, since the verticalvelocity field is the result of a complex interplay between physics and dynamics. It does show, however, that there is a strong feedback of the physics onto the dynamics; for instance RACMO, RCA and HIRLAM show significant differences in the vertical velocity field, although they are all limited-area models using identical dynamics and the same ECMWF boundary fields. In other words, the displayed differences for these three models are due to the different physics parametrization packages.

The cross-sections of relative humidity are shown in Fig. 3. Some care has to be taken here as the models use different methods to determine this variable. ARPEGE and MetO simply calculate the relative humidity with respect to the saturation specific humidity of water above $273 \mathrm{~K}$ and with respect to the saturation specific humidity of ice below $273 \mathrm{~K}$. All other models assume a mixed phase in the interval between $273 \mathrm{~K}$ and 238-261 K, and use different types of combination of the saturation specific humidity 

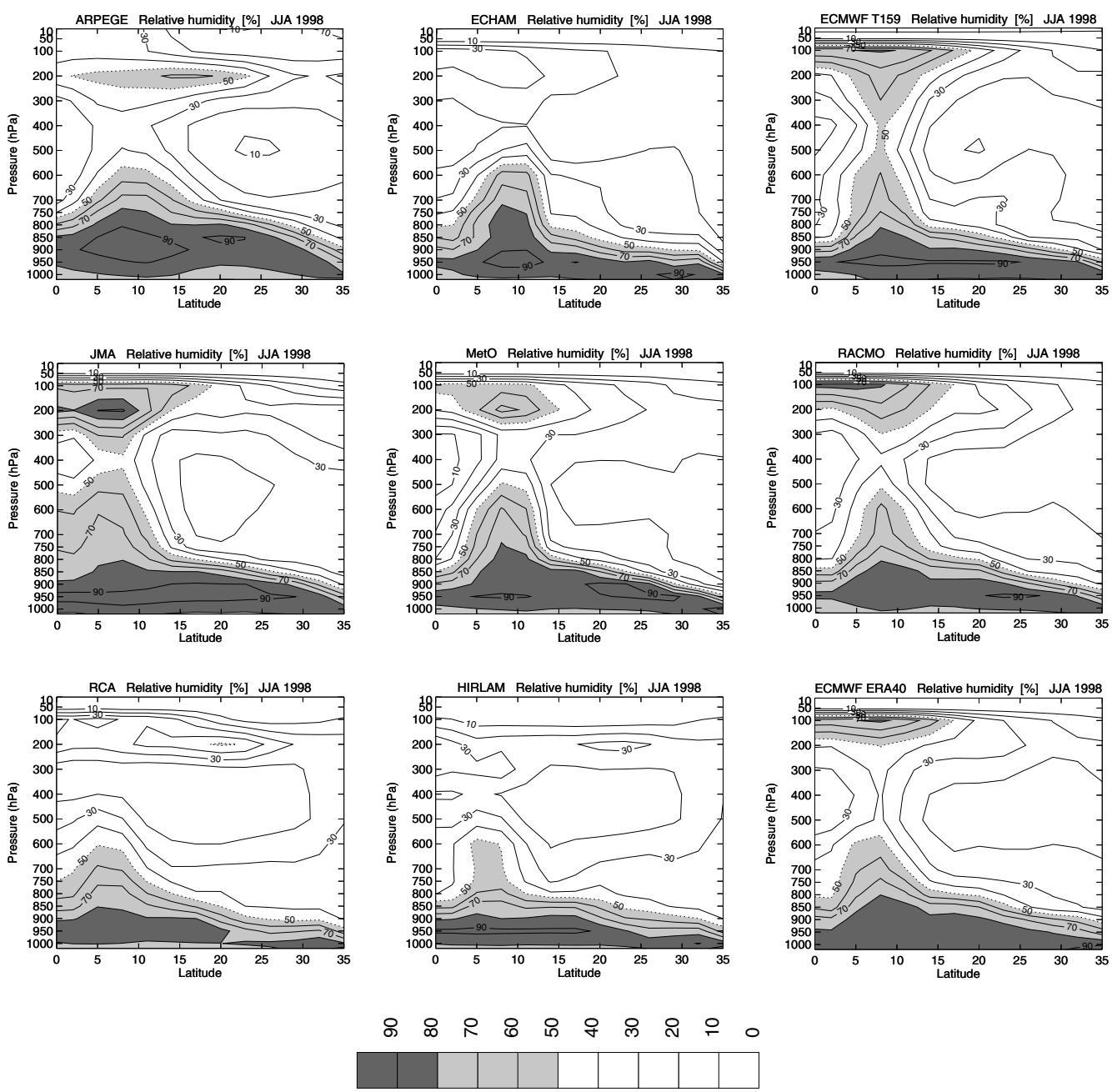

Figure 3. As Fig. 2, but for relative humidity.

of ice and water within this temperature interval. Again, all models seem to capture the general characteristics relatively well. In the subtropics, all models show moist planetary boundary-layer (PBL) air capped by a strong inversion and dry atmosphere above. The inversion height increases from the Sc regions to the deep tropics over increasing SST. The growth of the boundary-layer height, however, proceeds in different ways in the different models, and this has important consequences in terms of clouds and the radiative balance that is explored later in more detail. If we loosely define the boundarylayer height as the 50\% relative humidity level for the Sc and the trade-wind region, it can be observed that the ECMWF analysis indicates a boundary-layer top at $910 \mathrm{hPa}$ at $35^{\circ} \mathrm{N}$ that increases with latitude with at a rate of $500 \mathrm{~m}$ per $1000 \mathrm{~km}$. Most models have a similar behaviour in the range 400-600 m per $1000 \mathrm{~km}$. Only ARPEGE is an outlier, with a boundary layer that is typically $100 \mathrm{hPa}$ deeper, and also has a stronger deepening rate with latitude of $700 \mathrm{~m}$ per $1000 \mathrm{~km}$. In the ITCZ all models show relatively high values of relative humidity extending to the upper troposphere; however, the differences between the models are very significant. There is a clear relationship between the depth 

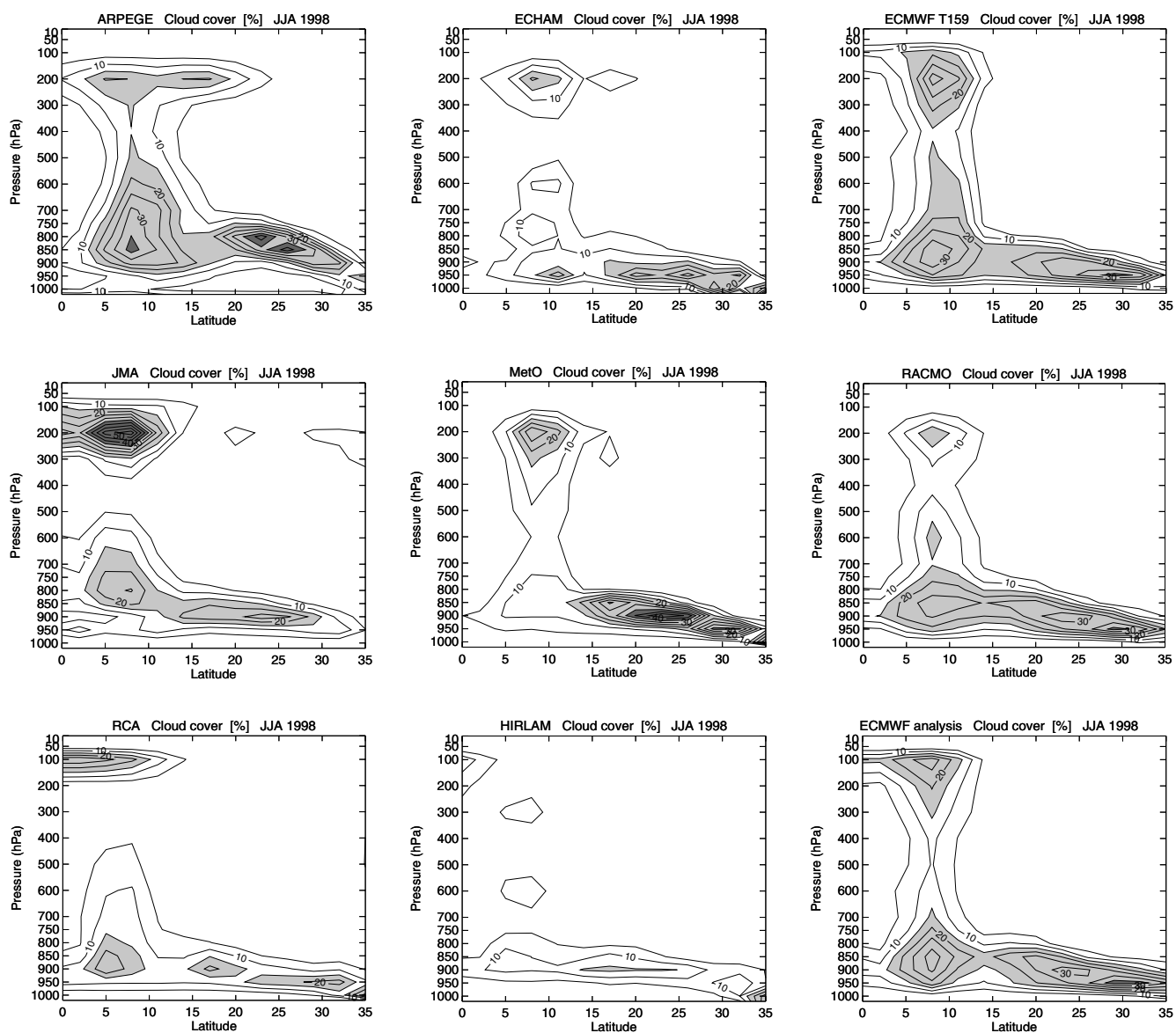

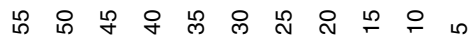

Figure 4. As Fig. 2, but for cloud cover.

of the upward velocity field and the vertical structure of the relative-humidity field. The models with relative humidity below $50 \%$ in the upper troposphere (ECHAM, RCA, HIRLAM) are all models with a shallow updraught branch. Only RACMO is a bit of an outlier, since it also has a rather weak updraught coinciding with a high relative humidity in the upper troposphere. While both the vertical velocity and the intensity of convective mixing determine the relative-humidity fields, it seems that the latter is more important, and that the velocity field mainly responds to the intensity of the convective mixing. For example, ECMWF and RACMO have very similar relative-humidity fields, whereas they differ significantly with respect to the velocity field. Since RACMO and ECMWF share the same convection scheme, this also suggests that the dynamics in RACMO responds differently to the intensity of the convection scheme than the dynamics of the ECMWF model.

Figure 4 shows the cross-sections of model cloud cover. Similar to the boundarylayer height, it can be seen that cloud-top height grows with increasing SST. Not surprisingly, the cloud-top height in ARPEGE is too high; at $20^{\circ} \mathrm{N}$ the ECMWF 
analysis (and most other models) shows a PBL top of around $800 \mathrm{hPa}$, while in ARPEGE the cloud top is around $700 \mathrm{hPa}$. The erroneous rapid growth of the boundarylayer height in ARPEGE is consistent with results of a single-column model version (Lenderink et al. 2004). Furthermore, MetO seems to have too high cloud-cover values in the trades up to values of $45 \%$, even larger than values found in the Sc region. In the deep tropics, HIRLAM and, to a lesser extent, RCA and ECHAM stand out as they produce low values of cloud cover above $500 \mathrm{hPa}$ in the ITCZ compared with the other models. The differences in cloud cover between the models are especially large in the ITCZ near the tropopause where cloud-cover values range between $0 \%$ and $50 \%$.

\section{(b) Hydrological fields and fluxes}

An important requisite for having realistic cloud fields in any model, is to have reliable estimates for the total column water vapour (TCWV). The results for TCWV along with SSM/I observations are shown in Fig. 5(a). As can be seen, the relative scatter between the different models and around the observations appears to be small at first sight. This is not surprising since the TCWV is a fundamental integral quantity that models should be able to simulate correctly if claims of a realistic simulation of the Hadley circulation are to be made. All models show the correct qualitative behaviour of going from a low value between 15 and $20 \mathrm{~kg} \mathrm{~m}^{-2}$ in the Sc regions to around $50 \mathrm{~kg} \mathrm{~m}^{-2}$ in the ITCZ. In an absolute sense, however, the errors in some models are large. ARPEGE overestimates TCWV on the whole with a typical value of $10 \mathrm{~kg} \mathrm{~m}^{-2}$. This bias is most likely related to the overestimation of the boundarylayer depth of ARPEGE, since it is the boundary layer where most of the humidity resides in. ARPEGE, MetO and JMA overestimate the peak value in the ITCZ by $5-10 \mathrm{~kg} \mathrm{~m}^{-2}$, while HIRLAM and RCA underestimate this peak by a similar value and also position the peak too far to the south. In the trades, all models except ARPEGE give approximately the correct results, while in the Sc regions the TCWV is overpredicted by HIRLAM, RCA, and to a lesser extend by JMA and ARPEGE. The overestimation of TCWV by JMA might be related to the slightly biased prescribed SST by this model.

Figure 5(b) shows the latitude variation of the total cloud cover (TCC) for each model along with observations from ISCCP. There is a general pattern followed by most models. Most models, with the exception of the MetO and RCA, strongly underpredict the Sc cloud cover. On the other hand, most models overpredict cloud cover associated with the deep convection in the ITCZ. As a result, since most models also overpredict the cloud cover of the shallow trade-wind cumuli, only a few models exhibit the characteristic minimum of the cloud cover in the trades between 15 and $20^{\circ} \mathrm{N}$ that is so clearly present in the observations. Note that the errors are large; in the Sc region cloud fraction is underestimated by 30 to $50 \%$, while the overestimation in the trades and the ITCZ is of the order of $20 \%$.

The consequences in terms of cloud water are investigated by analysing the latitude variation of the liquid-water path (LWP) that is shown in Fig. 5(c) for the different models, together with SSM/I estimates from three different satellites. In general, the results confirm the previous findings; the models underestimate LWP in the Sc areas and overestimate LWP in the equatorial regions. Observations in the Sc regions indicate typical values for LWP of typically 90-100 $\mathrm{g} \mathrm{m}^{-2}$. Only MetO and ECHAM predict similar values, while the other models underpredict LWP with negative biases up to $80 \mathrm{~g} \mathrm{~m}^{-2}$. Some of these low values are similar to the differences reported by Duynkerke and Teixeira (2001). Note that some models (e.g. RCA) that predict reasonable values for cloud cover in the Sc regions still fail to give realistic values for LWP. On the other hand ECHAM underestimates cloud cover but gives reasonable values for LWP in the 

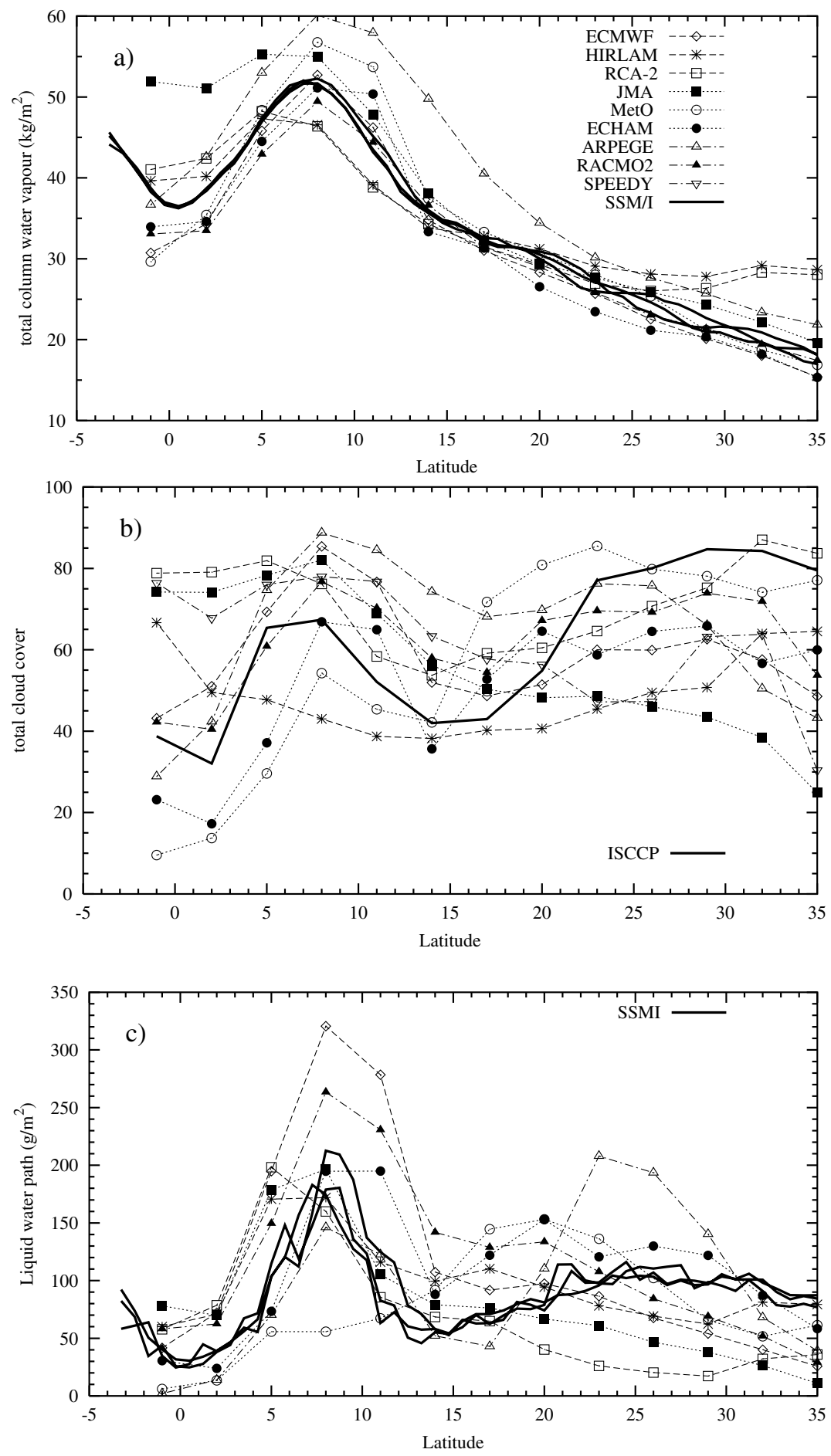

Figure 5. June/July/August averaged fields for all models of (a) integrated water vapour column together with SSM/I observations, (b) total cloud cover together with ISCCP observations, (c) integrated liquid water path (LWP) together with SSM/I observations, (d) precipitation rates together with GPCP and TRMM observations, (e) latent-heat surface fluxes together with climatology and ECMWF analysis, and (f) precipitation minus surface evaporation. 

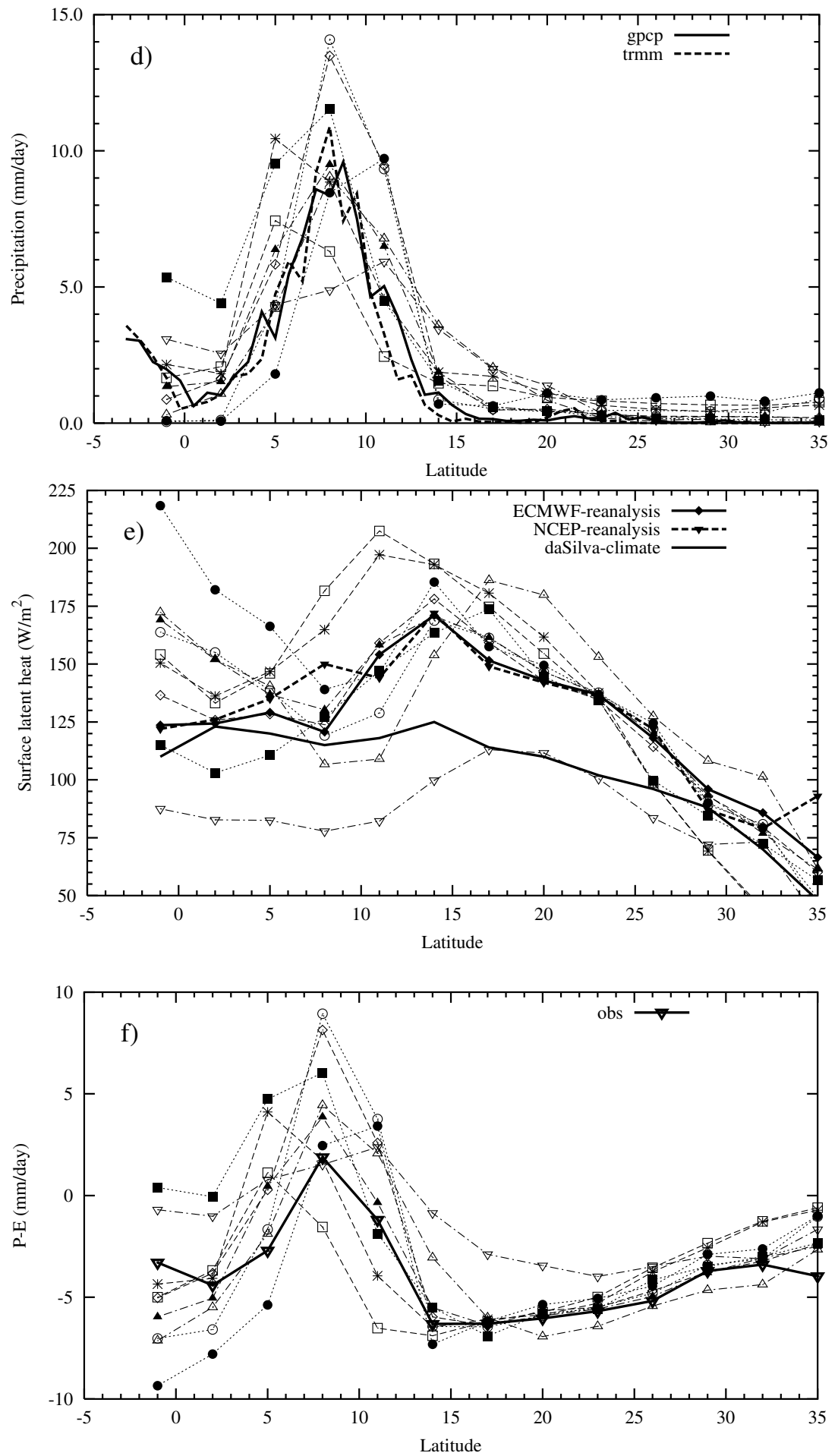

Figure 5. Continued. 
Sc region. In general, models that use liquid water as a prognostic variable but estimate cloud fraction diagnostically in a rather independent way may show these unrealistic features. Most models overestimate the LWP in the trades around $15^{\circ} \mathrm{N}$, which is consistent with the systematic overestimation of cloud cover of most models in these regions. In the ITCZ, ECMWF and RACMO strongly overpredict the observed LWP peak value of around $200 \mathrm{~g} \mathrm{~m}^{-2}$, while MetO completely misses the LWP peak and underestimates LWP therefore by $150 \mathrm{~g} \mathrm{~m}^{-2}$.

The impact on the mean precipitation can be seen in Fig. 5(d). Precipitation observed by TRMM and GPCP peaks in the ITCZ at around $8^{\circ} \mathrm{N}$, with values of $10-11 \mathrm{~mm} \mathrm{day}^{-1}$. ECMWF and MetO have positive biases of around $5 \mathrm{~mm} \mathrm{day}{ }^{-1}$, which confirms the previous results of Teixeira (1999). Only RCA and, especially, SPEEDY underestimate the peak intensity in the tropics and also fail to model the correct position of the precipitation maximum. SPEEDY and ARPEGE predict too broad a precipitation peak, causing too much precipitation in the trades. Much of the findings concerning the location of the precipitation maximum and the width of the tropical precipitation peak are in line with the results of LWP and the vertical velocity. In the Sc regions the models produce values homogeneously scattered between 0 and $1 \mathrm{~mm} \mathrm{day}^{-1}$. The observations show, basically, no precipitation but the satellite observations used are not very reliable for these low drizzle rates and precise data on drizzle rates on this seasonal scale are lacking. However, recent observational campaigns (Stevens et al. 2003) suggest that Sc may drizzle more than previously accepted.

An important parameter for the hydrological cycle is the surface latent-heat flux. Unfortunately there were no reliable measurements available for this parameter and so we used three surrogates: (1) climatology as determined by da Silva et al. (1994), (2) ECMWF reanalysis, and (3) NCEP reanalysis. Results are shown in Fig. 5(e). Both reanalysis results indicate an increase of the latent-heat fluxes from the Sc regions, with values of $80-90 \mathrm{~W} \mathrm{~m}^{-2}$ to peak values of around $170 \mathrm{~W} \mathrm{~m}^{-2}$ in the trades. Further towards the ITCZ the fluxes decrease again to values of around $125 \mathrm{~W} \mathrm{~m}^{-2}$. These reanalysis results are in sharp contrast to the da Silva (1994) climatology (see Fig. 5(e))

Most models show a qualitatively similar behaviour to that of the ECMWF and NCEP reanalyses, with maximum values in the trades. However, since the observations that actually go into the analyses are sparse, differences between the reanalyses and the 'true' surface fluxes can be large. Outliers are HIRLAM and RCA with too high peak values of around $200 \mathrm{~W} \mathrm{~m}^{-2}$ and SPEEDY with too low values, especially in the deep tropics. Furthermore, it is surprising to see that almost all models have substantially higher fluxes than the reanalyses and climatology at the equator, with biases up to $100 \mathrm{~W} \mathrm{~m}^{-2}$.

We finally show in Fig. 5(f) precipitation minus the surface evaporation $(P-E)$. In the Sc and the trade-wind regions all models (except SPEEDY) agree reasonably well with a negative $P-E$ decreasing from $-1 \mathrm{~mm}^{-1 a y}{ }^{-1}$ at $35^{\circ} \mathrm{N}$ to $-6 \mathrm{~mm}^{\text {day }}{ }^{-1}$ at $15^{\circ} \mathrm{N}$. In the ITCZ, all models show a positive $P-E$, but the absolute values range from marginally positive (RCA: $1 \mathrm{~mm} \mathrm{day}^{-1}$ ) to values of as much as $9 \mathrm{~mm} \mathrm{day}^{-1}$.

\section{(c) Radiative fluxes}

We finally want to explore the impact of the modelled hydrological cycle on the radiative fluxes of the models, both at the TOA as well as near the surface. The global energy balance of the atmosphere is, to a large extent, determined through the TOA radiative fluxes and the uncertainty in these fluxes can, for a large part, be attributed to uncertainties in the predicted cloud amounts. On the other hand, the Sc regions do have a 
significant cooling effect on the underlying ocean. Therefore, an underprediction of the Sc amounts causes an overprediction of the net surface heat flux into the ocean, which can lead to positive SST biases in coupled atmosphere-ocean models. In this section we quantify the typical biases in the modelled radiative fluxes.

Figure 6(a) shows the corresponding results for the JJA averaged OLR together with observations from CERES. The OLR values of HIRLAM, RCA and SPEEDY have a deviant behaviour; this is likely to be due not only to the biases in the cloud amounts but also to flaws in the radiation-scheme formulation. In the rest of the discussion we exclude these models. In the Sc regions the differences between the other models and the observations are relatively small (with roughly the same number of models above and below the observations), mainly because the OLR is not so sensitive to low-level cloud amount as it is to high- and medium-level clouds. However, it is a somewhat disturbing that these differences, although quite low when compared with the biases in the ITCZ, can reach values of up to almost $20 \mathrm{~W} \mathrm{~m}^{-2}$. In the deep tropics, most models underestimate the OLR, with the exception of ECHAM and RACMO. The negative biases range from $10 \mathrm{~W} \mathrm{~m}^{-2}$ (MetO, ARPEGE) up to $30 \mathrm{~W} \mathrm{~m}^{-2}$ (JMA, ECMWF). These results are consistent with the amounts of high cloud cover predicted by the models.

The net short-wave radiation at the TOA (SWTOA) is shown in Fig. 6(b), together with CERES observations. It can be seen clearly that, in general, most model atmospheres are not reflective enough in the Sc regions and are too reflective in the deep tropics. This confirms again that the models have, in general, a lack of clouds in the Sc areas and too many clouds in the ITCZ. In the Sc regions ECMWF, RCA, JMA, ARPEGE and RACMO overestimate SWTOA the most, which is consistent with underprediction of cloud cover and LWP in these models, by $60-80 \mathrm{~W} \mathrm{~m}^{-2}$. In the ITCZ, negative biases ranging from 20 to $80 \mathrm{~W} \mathrm{~m}^{-2}$ of SWTOA is clearly visible for all models except MetO.

The downward short-wave fluxes at the surface are shown in Fig. 6(c), along with observations from CERES. These results are somewhat the mirror image of the TOA short-wave radiation results; the model atmospheres are too transparent in the Sc regions and reflect (and/or absorb) too much in the trades and the tropics. Again, this is directly related with the underestimation of clouds and LWP in the Sc regions and an overestimation of these fields elsewhere. The positive biases of the short-wave radiation in the Sc region are typically of the order of $60 \mathrm{~W} \mathrm{~m}^{-2}$. Only MetO and ECHAM give correct fluxes in these regions. On the other hand, underprediction of the order of $60 \mathrm{~W} \mathrm{~m} \mathrm{~W}^{-2}$ of the surface short-wave fluxes can be seen in the trades and the tropics.

Although the prime suspect for the high short-wave transmissivity in the Sc regions is most likely the underprediction of the LWP, it cannot be ruled out also that biases due to the formulation of the radiation schemes in the models contaminate the results. One way to address this issue is to examine correlations between the LWP

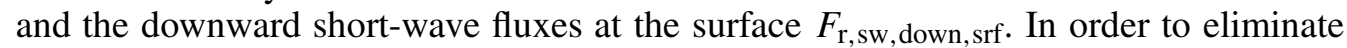
trivial dependencies of $F_{\mathrm{r}, \mathrm{sw} \text {, down, srf }}$ on the incoming short-wave radiation at the TOA,

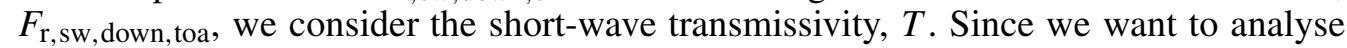
only model output with stratocumulus clouds, only model output for the four grid points between $25^{\circ}$ and $35^{\circ} \mathrm{N}$ with a total cloud cover larger than $40 \%$ were selected. For each of these grid points the monthly averaged transmissivity is calculated between 18 UTC and 00 UTC which is a six-hour time interval around local noon. We consider

$$
\langle T\rangle=\frac{\left\langle F_{\mathrm{r}, \mathrm{sw}, \text { down }, \mathrm{srf}}\right\rangle}{\left\langle F_{\mathrm{r}, \mathrm{sw}, \text { down }, \text { toa }}\right\rangle},
$$



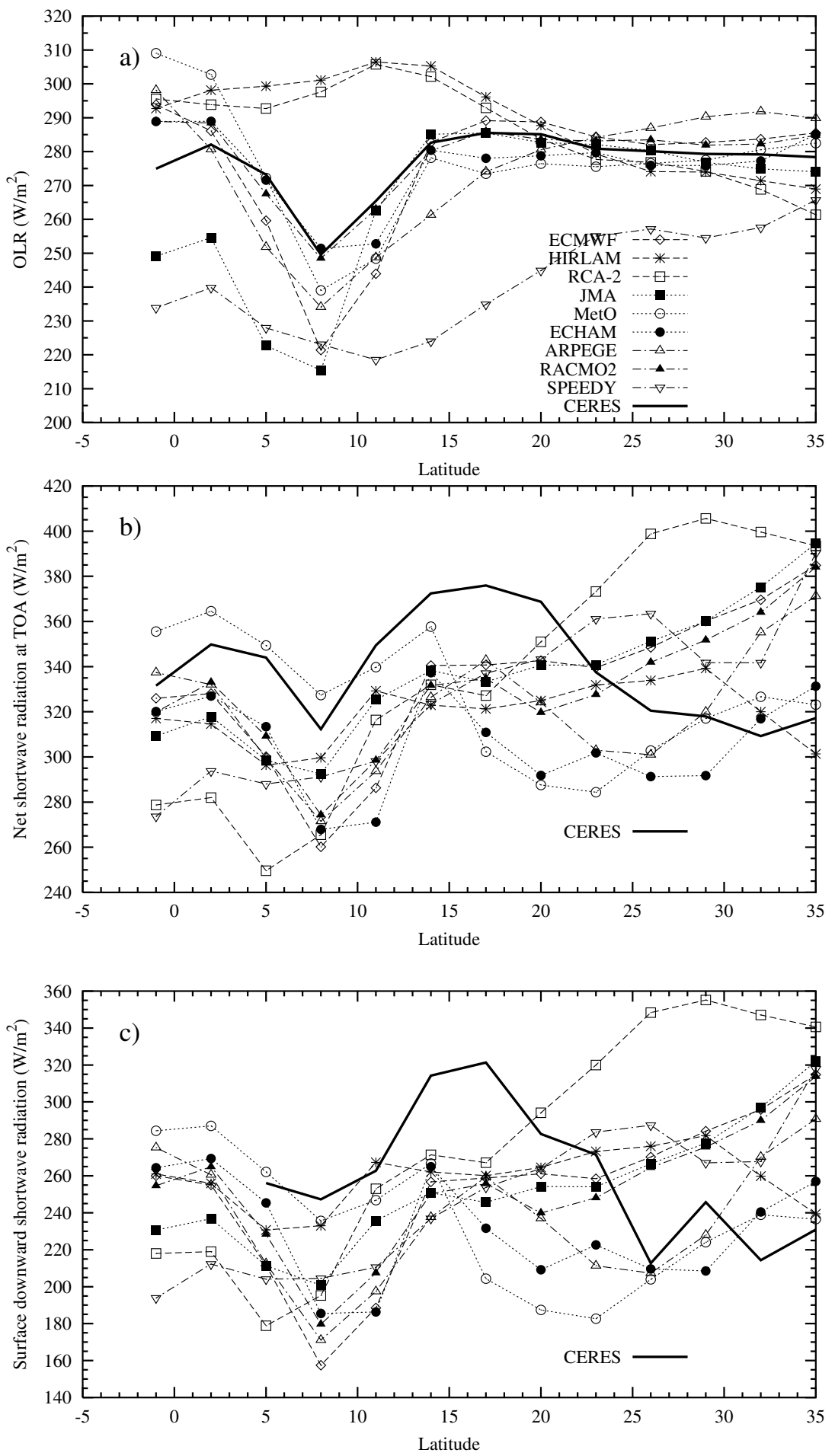

Figure 6. June/July/August averaged fields for all models of (a) outgoing long-wave radiation, (b) net short-wave radiation at the top of the atmosphere, and (c) downward surface short-wave radiation, together with observations from CERES. 

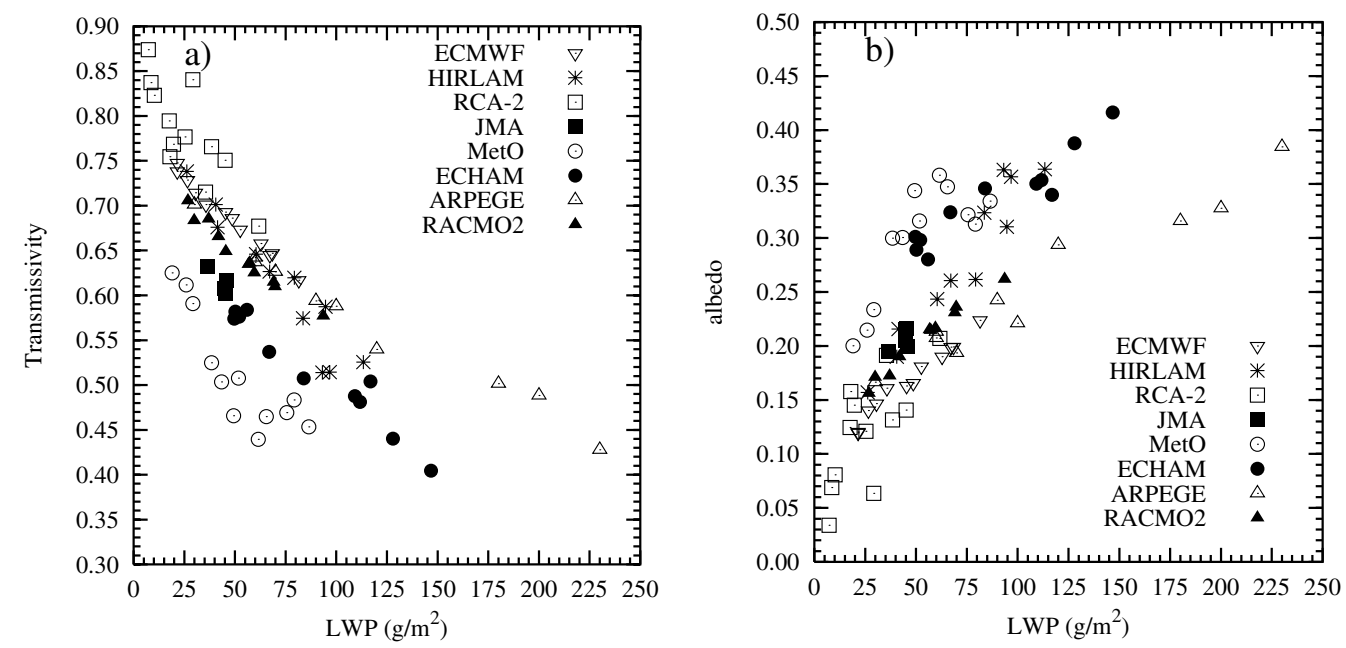

Figure 7. Scatter plots of (a) the transmissivity, and (b) the planetary albedo as functions of liquid-water path for grid points with stratocumulus.

where the brackets denote a time average. The six-hour time interval has been used since some models supplied their radiative fluxes only as six-hour averages. In Fig. 7(a) the LWP versus the transmissivity is displayed for all models. If all models used an identical radiation scheme, treating clouds in an identical way, one would expect that the points would scatter around one single curve, irrespective of whether the models predict the LWP amount correctly or not. The results show that ECMWF, RACMO, RCA, HIRLAM and ARPEGE scatter around one imaginary curve. It should be noted, however, that ECMWF and RACMO use an identical radiation scheme. The points of JMA, ECHAM, and especially MetO, demonstrate that these models have a substantially smaller transmissivities. A similar message is contained in the planetary albedo (Fig. 7(b))

$$
\langle A\rangle=\frac{\left\langle F_{\mathrm{r}, \text { sw }, \text { up }, \text { toa }}\right\rangle}{\left\langle F_{\mathrm{r}, \mathrm{sw}, \text { down }, \text { toa }}\right\rangle},
$$

where the brackets denote the same time average as for the transmissivity. MetO and ECHAM exhibit a systematically larger reflectivity than the other models for a given LWP. It is difficult to make speculations on the cause of these differences. However, one option could lie in how cloud inhomogeneity is treated in the various models; ECMWF and RACMO reduce their cloud albedo by a factor 0.7 with respect to the planeparallel calculations, which enhances the cloud transmissivity considerably. This has to be contrasted with the MetO and ECHAM that treat their clouds simply as plane parallel. A careful analysis of these data with observations is left to future studies.

\section{DisCUSSION AND PERSPECTIVES}

In general, it can be seen that all models seem to reproduce the broad qualitative properties of the Hadley circulation in a relatively realistic way. However, many of the physical characteristics studied vary widely from model to model. All the quantities analysed are directly or indirectly linked to cloud properties, and the results show that, although there is a large spread in the results of the different models, some typical 
behaviours are common among most models: (1) most models underestimate clouds in the stratocumulus regions with the inevitable consequences in terms of short-wave radiative fluxes; (2) most models overestimate clouds in the ITCZ and the trades, with important connections in terms of long-wave radiative properties and precipitation.

It is encouraging to see that the only model result (MetO) that included improved parametrizations for stratocumulus and shallow cumulus developed during the EUROCS project, turned out to have the best cloud representation for these cloud types. Thus, it is to be expected that the other participating models will improve similarly when they rerun this case, since a number of the observed deficiencies were also present in the individual case studies with SCMs and LES models. In particular, the case study of diurnal cycle of shallow cumulus convection (Lenderink et al. 2004) also reported a collective overestimation of cloud cover and cloud liquid water. Also some of the individual model deficiencies, such as the unrealistic deep PBL of the ARPEGE model, were present in this study. Apparently these problems can be isolated to a single case with prescribed conditions and for the causes and solutions of these deficiencies we refer to Lenderink et al. (2004).

The underprediction of clouds in the Sc regions can be due to errors in at least three physical mechanisms: (1) incorrect large-scale forcing, (2) too intense drizzle, and (3) too much entrainment. It is difficult to point out which is the prime suspect. However, since the subsidence rate of most models is quite close to what one would expect from assuming background radiatively driven subsidence, the underprediction of cloud cover is most likely to be due to one of (or a combination of) the last two of these mechanisms. Since the LES EUROCS stratocumulus case study (Duynkerke et al. 2004) studied only non-drizzling stratocumulus and concentrated mainly on entrainment, it cannot resolve this issue. However, the fact that SCM simulations for the non-drizzling stratocumulus in that study do not show a systematic underestimation of cloud amounts suggests that the use of a too active drizzle parametrization is likely to be one of the reasons of the low simulated LWP values in most model runs. In any case, drizzle is probably a key process in the whole stratocumulus riddle. Lenderink and Siebesma (2004) have argued that the extreme sensitivity between LWP and subsidence (Duynkerke et al. 2004; Chlond et al. 2004) can be strongly reduced by introducing drizzle. They also argued that steady-state stratocumulus fields are possible with realistic subsidence rates of around $0.05 \mathrm{~Pa} \mathrm{~s}^{-1}$ if, again, drizzle is taken into account. Nevertheless, some important conclusions can be drawn from the EUROCS LES stratocumulus case study (Duynkerke et al. 2004). First, it is important to control the entrainment process in any turbulence mixing parametrization, either by prescribed entrainment rates (Lock 2004) or by using a turbulent kinetic energy (TKE) scheme that is formulated in moist conserved variables and has a high enough vertical resolution (Lenderink and Holtslag 2000). Furthermore, activation of the convection scheme may cause extra turbulent mixing, and hence extra entrainment that might erode the stratocumulus clouds. It is, therefore, important that the turbulence and the convection scheme in any parametrization package operate in a coherent way. Finally, care needs to be taken with the numerical discretization effects in the parametrizations, especially near the top of the stratocumulus layer. It should be noted that the improved version of MetO takes into account all these three points with a positive impact on the representation of stratocumulus (Lock 2004).

Many of the findings in the case studies for deep convection (Guichard et al. 2004) need to be evaluated in a 3D GCM context, and the present case offers an excellent and simple test. A recent study on a new trigger function in the ECMWF model (Jakob and Siebesma 2003) has shown that the cloud climatology in the ITCZ is extremely sensitive to the trigger mechanism used. 
The present initial analysis has been rather superficial. Only averages over the whole JJA period have been analysed. However, much more detailed model and observational data are available to analyse such as, for instance, the monthly averaged diurnal cycle. More profound studies of the physical details of the models are left to the future. The special strength of these types of study is that different aspects (in this case clouds and radiation and, to a lesser extent, dynamics) are evaluated in a coherent way. Since remote sensing techniques are advancing fast, model evaluations like the present one will put more constraints on the parametrizations of clouds and radiation. It will become increasingly more difficult to have a correct radiative energy balance in a climate model along with an incorrect cloud climatology. Through these types of constraint, and through critical evaluations, the scientific community will be forced to develop further physically sound parametrizations that ultimately result in models that are capable of simulating our climate system with increasing realism.

Let us finally stress that this type of model development and evaluation is only possible because modellers are brought together through international networks and projects such as EUROCS and GCSS, and through initiatives such as GCSS-DIME that are indispensable in helping to close the gap between models and observations.

\section{ACKNOWLEDGEMENTS}

This work has benefited greatly from discussions during the EUROCS workshops in Lisbon, de Bilt, Utrecht and Madrid. This study has been made with financial support from the European Union (Contract number EVK2-CT-1999-00051). The GEWEX Cloud System Study Data Integration for Model Evaluation (GCSS-DIME) has played a crucial role in supplying and postprocessing observational data. We would therefore like thank William B. Rossow, George Tselioudis, Anatasia Gentilcore and Ely N. Duenas (NASA Goddard Institute for Space Studies (GISS)) for all their efforts. We would also like to thank Alice Fan (NASA) for providing surface short-wave radiation data based on CERES. Finally, the many useful comments from two anonymous reviewers, which helped to improve the manuscript substantially, is gratefully acknowledged.

\section{APPENDix A}

\section{Model details}

The three global climate models (ECHAM, ARPEGE, SPEEDY) all are spectral models. SPEEDY (Simplified parametrizations, PrimitivE-Equation DYnamics) is intermediate complexity model with a parametrization package that has been specially designed to work in models with just a few vertical levels. It is the model with the lowest resolution with only seven levels in the vertical and a spectral truncation at total wave number 30 (T30L7). ECHAM and ARPEGE are state-of-the-art climate models. A brief description of the physics package can be found in the appendix of the paper by Lenderink et al. (2004) that deals with an intercomparison case study with singlecolumn versions of these models. However, the Max Planck Institute is using a newer version (ECHAM-5) in this present study. One of the main differences with respect to ECHAM-4 is the use of a new statistical cloud scheme (Tompkins 2002).

The three global numerical weather-forecasting models (ECMWF, MetO, JMA) operate typically at a higher resolution (see Table 1). The Met Office model is the only model from which results were submitted for both the standard version and one for an improved version. In this paper we only show results of the improved new version which has been described by Lock (2004). The ECMWF model uses 
version Cycle 23r3 (Gregory et al. 2000), which has essentially the same physics package as in the cumulus single-column model intercomparison study described by Lenderink et al. (2004). The JMA (Japan Meteorological Agency) employs the level2 turbulence closure scheme of Mellor and Yamada (1974) to determine the effects of vertical diffusion. For convection, an economical version of the Arakawa-Schubert scheme (Arakawa and Schubert 1974) is used to simulate penetrative (deep) convection. Cloud fraction and cloud water are determined using a statistical scheme.

The three regional models (HIRLAM5, RCA-2 and RACMO-2) are grid-point models and operate on the highest resolution and use identical dynamical cores. They also use the same ECMWF operational analysis as boundaries. Therefore, the models only differ from each other through the use of different physics packages. The physics package of the RACMO-2 model is identical to the one in the ECMWF Cycle 23r4 model (Gregory et al. 2000). The HIRLAM5 physics package has been described briefly by Lenderink et al. (2004). The RCA-2 model uses a Kain and Fritsch (1990) scheme for convection, clouds are diagnosed using a cloud scheme based on relative humidity and condensation, microphysics and precipitation are estimated according to Rasch and Kristjánsson (1998).

Arakawa, A. and Schubert, W. H.

Betts, A. K. and Ridgway, W.

Browning, K. A.

Chlond, A., Müller, F. and Sednev, I.

Da Silva, A., Young, A. C. and Levitus, $\mathrm{S}$.

Duynkerke, P. G. and Teixeira, J.

Duynkerke, P. G., De Roode, R., Van Zanten, M. C., Calvo, J., Cuxart, J., Cheinet, S., Chlond, A., Grenier, H., Jonker, P. J., Köhler, M., Lenderink, G., Lewellen, D., Lappen, C.-L., Lock, A. P., Moeng, C.-H., Müller, F., Olmeda, D., Piriou, J.-M., Sánchez, E. and Sednev, I.

Gibelin, A.-L. and Déqué, M.

Gregory, D., Morcrette, J.-J., Jakob, C., Beljaars, A. C. M. and Stockdale, $\mathrm{T}$.

Guichard, F., Petch, J. C., Redelsperger, J.-L.,

Bechtold, P.,

Chaboureau, J.-P., Cheinet, S., Grabowski, W., Grenier, H., Jones, C. G., Köhler, M., Piriou, J.-M., Tailleux, R. and Tomasini, M.

\section{REFERENCES}

1974

1988

1993

2004

1994

2001

2004

2003

2000

2004
Interaction of a cumulus cloud ensemble with the large-scale environment. J. Atmos. Sci., 31, 674-701

Coupling of the radiative, convective and surface fluxes over the equatorial Pacific. J. Atmos. Sci., 45, 522-536

The GEWEX Cloud System Study (GCSS). Bull. Amer. Meteorol. Soc., 74, 387-399

Numerical simulation of the diurnal cycle of marine stratocumulus during FIRE-An LES and SCM modelling study. Q. J. R. Meteorol. Soc., 130, 3297-3321

'Atlas of surface marine data, Vol. 1: Algorithms and procedures'. NOAA Atlas NESDIS 6, National Environmental Satellite Data and Information Service, Silver Spring, MD, USA

Comparison of the ECMWF reanalysis with FIRE I observations: Diurnal variation of marine stratocumulus. J. Climate, 14, 1466-1478

Observations and numerical simulations of the diurnal cycle of the EUROCS stratocumulus case. Q. J. R. Meteorol. Soc., 130, 3269-3296

Anthropogenic climate change over the Mediterranean region simulated by a global variable resolution model. Climate Dyn., 20, 327-339

Revision of convection, radiation and cloud schemes in the ECMWF integrated forecasting system. Q. J. R. Meteorol. Soc., 126, 1685-1710

Modelling the diurnal cycte of deep precipitating convection over land with cloud-resolving models and single-column models. Q. J. R. Meteorol. Soc., 130, 3139-3172 
Hollinger, J. R.

1987

Huffman, G. J.

1997

Huffman, G. J., Adler, R., Rudolf, B., Schneider, U. and Keehn, P.

Huffman, G. J., Adler, R. F., Arkin, P. A., Chang, A., Ferraro, R., Gruber, A., Janowiak, J., Joyce, R. J., McNab, A., Rudolf, B., Jakob, C.

Schneider, U. and Xie, P.

Jakob, C. and Siebesma, A.

Jones, C. G.

Kain, J. S. and Fritsch, J. M.

Klein, S. A. and Jakob, C.

Kummerow, C., Barnes, W., Kozu, T., Shiue, J. and Simpson, J.

Lenderink, G. and Holtslag, A.

Lenderink, G. and Siebesma, A. P.

Lenderink, G., van den Hurk, B., van Meijgaard, E., van Ulden, A. P. and Cuijpers, J. W. M.

Lenderink, G., Siebesma, A. P., Cheinet, S., Irons, S., Jones, C. G., Marquet, P., Müller, F., Olmeda, D., Calvo, J., Sánchez, E. and Soares, P. M. M.

Lock, A. P.

Matsumura, T., Ohizumi, M., Kitagawa, H. and Nakagawa, M.

Mellor, G. L. and Yamada, T.

Molteni, F.

Norris, J. and Weaver, C.

Randall, D. A., Krueger, S. K., Bretherton, C. S., Curry, J. A., Moncrieff, M., Ryan, B. F., Miller, M. J., Rossow, W. B., Tselioudis, G. and Wielicki, B. Rasch, P. J. and Kristjánsson, J. E.
'Special Sensor Microwave/Imager user's guide'. Tech. Report 1, Naval Research Laboratory, Monterey, CA, USA

'The Global Precipitation Climatology Project monthly mean precipitation data set'. WMO/TD 808WMO, World Meteorological Organization, Geneva, Switzerland

1995 Global precipitation estimates based on a technique for combining satellite-based estimates, rain gauge analysis, and NWP model precipitation information. J. Climate, 8, 1284-1295

1997 The Global Precipitation Climatology Project (GPCP) combined precipitation data set. Bull. Amer. Meteorol. Soc., 78, 5-20
2003

2003

2001

1990

1999

1998

2000

2004

2003

2004

2004

2002

1974

1996

1998
An improved strategy For the evaluation of cloud parametrizations in GCM's. Bull. Amer. Meteorol. Soc., 84, 1387-1401

A new subcloud model for mass-flux convection schemes; Influence on triggering, updraught properties and model climate. Mon. Weather Rev., 131, 441-486

'A brief description of RCA2 (Rossby Centre Atmosphere Model Version 2)'. SWECLIM Newsletter 11, Swedish Meteorology and Hydrology Institute, Norrköping, Sweden

A one-dimensional entraining/detraining plume model and its application in convective parameterization. J. Atmos. Sci., 47, 2784-2802

Validation and sensitivities of frontal clouds simulated by the ECMWF model. Mon. Weather Rev., 127, 2514-2531

The Tropical Rainfall Measuring Mission (TRMM) sensor package. J. Atmos. Ocean. Tech., 15, 809-817

Evaluation of the kinetic energy approach for modelling turbulent fluxes in stratocumulus. Mon. Weather Rev, 128, 244-258

On the role of drizzle in stratocumulus and its implications for large-eddy simulation. Q. J. R. Meteorol. Soc., 130, 3429-3434

'Simulation of present-day climate in RACMO2: first results and model developments'. Tech. Rep. 252, KNMI, de Bilt, The Netherlands

The diurnal cycle of shallow cumulus clouds over land: A singlecolumn model intercomparison study. Q. J. R. Meteorol. Soc., 130, 3339-3364

The sensitivity of a GCM's marine stratocumulus to cloud-top entrainment. Q. J. R. Meteorol. Soc., 130, 3323-3338

'Outline of the operational numerical weather prediction at the Japan Meteorological Agency. 4.2. Global spectral model'. Tech. Rep. JMA-GSM0103, Japan Meteorological Agency, Tokyo, Japan

A hierarchy of turbulent-closure models for planetary boundary layers. J. Atmos. Sci., 31, 1791-1806

Atmospheric simulations using a GCM with simplified physical parameterizations. I: Model climatology and variability in multi-decadal experiments. Climate Dyn., 20, 175-191

Improved techniques for evaluating GCM cloudiness applied to the NCAR CCM3. J. Climate, 14, 2540-2550

Confronting models with data: The GEWEX clouds systems study. Bull. Amer. Meteorol. Soc., 84, 455-469

A comparison of the CCM3 model climate using diagnosed and predicted condensate parameterizations. J. Climate, 11, 1587-1614 
Reynolds, R. W., Rayner, N. A., Smith, T. M, Stokes, D. C. and Wang, W.

Roeckner, E., Bengtsson, L.,

Christoph, M., Claussen, M.,

Dumenil, L., Esch, M.,

Giorgetta, M., Schlese, U. and

Schulzweida, U.

Rossow, W., Garder, L., Lu, P. and Walker, A.

Simpson, J. C., Kummerow, C., Tao, W. K. and Adler, R. F. Stevens, B., Lenschow, D. H., Vali, G., Gerber, H.,

Bandy, A., Blomquist, B.,

Brenguier, J.-L.,

Bretherton, C. S., Burnet, F.,

Campos, T., Chai, S.,

Faloona, I., Friesen, D.,

Haimov, S., Laursen. K., Lilly, D. K., Loehrer, S. M.,

Malinowski, S. P., Morely, B.,

Petters, M. D., Rogers, D. C.,

Russell, L., Savik-Jovcic, V.,

Snider, J. R., Straub, D.,

Szumowski, J., Takagi, H.,

Thorton, D. C., Tschudi, M.,

Twohy, C., Wetzel, M. and

van Zanten, M. C.

Teixeira, J.

Tompkins, A.

Tselioudis, G. and Jakob, C.

Tselioudis, G., Zhang, Y. and Rossow, W. B.

Undén, P., Rontu, L., Jarvinen, H., Lynch, P., Calvo, J., Cats, G., Cuxart, J., Eerola, K.,

Fortelius, C.,

Garcia-Moya, J. A., Jones, C., Lenderink, G., McDonald, A., McGrath, R., Navascues, B.,

Nielsen, N. W., Odegaard, V., Rodriguez, E.,

Rummukainen, M., Room, R., Sattler, K., Sass, B. H.

Savijärvi, H., Schreur, B. W., The, H. and Tijm, S.

Webb, M., Senior, C., Bony, S. and Morcrette, J.-J.

Webster, S., Brown, A. R., Cameron, D. R. and Jones, C. P.

Wentz, F.

Wentz, F. and Spencer, R.
2002

1996

2003
An improved in situ and satellite SST analysis for climate. J. Climate, 15, 1609-1625

'The atmospheric general circulation model ECHAM-4: Model description and simulation of present-day climate'. Tech. Rep. 218, Max-Planck-Institut für Meteorologie, Hamburg, Germany

'International satellite cloud climatology project (ISCCP): documentation of cloud data'. Tech. Rep. WMO/TD 266, World Meteorological Organization, Geneva, Switzerland

On the Tropical Rainfall Measuring Mission (TRMM). Meteorol. Atmos. Phys., 60, 19-36

Dynamics and chemistry of marine stratocumulus-DYCOMS-II. Bull. Amer. Meteorol. Soc., 84, 579-593

'The impact of increased boundary layer vertical resolution on the ECMWF forecast system'. Tech. Rep. 268, European Centre for Medium-Range Weather Forecasts, Reading, UK

A prognostic parameterization for the subgrid-scale variability of water vapor and clouds in large-scale models and its use to diagnose cloud cover. J. Atmos. Sci., 59, 1917-1942

Evaluation of midlatitude cloud properties in a weather and a climate model: Dependence on dynamic regime and spatial resolution. J. Geophys. Res., 107, 4781-4781

Cloud and radiation variations associated with northern midlatitude low and high sea level pressure regimes. J. Climate, 13, $312-327$

'HIRLAIM-5 scientific documentation.'. Tech. Rep., Swedish Meteorology and Hydrology Institute, Norrköping, Sweden

Combining ERBE and ISCCP data to assess clouds in the Hadley Centre, ECMWF and LMD atmospheric climate models. Climate Dyn., 102, 8703-8718

Improvements to the representation of orography in the Met Office Unified Model. Q. J. R. Meteorol. Soc., 129, 1989-2010

A well-calibrated ocean algorithm for SSM/I. J. Geophys. Res., 17, 905-922

$\mathrm{SSM} / \mathrm{I}$ rain retrievals within a unified all-weather ocean algorithm. J. Atmos. Sci., 55, 1613-1627 
Wielicki, B. A., Barkstrom, B. R., Harrison, E. F., Lee, R. B. III, Smith, G. L. and Cooper, J. E. Williams, K., Ringer, M. and Senior, C.
1996 Clouds and the Earth's Radiant Energy System (CERES): An earth observing system experiment. Bull. Amer. Meteorol. Soc., 77, 853-868

2003 Evaluating the cloud response to climate change and current climate variability. Climate Dyn., 20, 705-721 